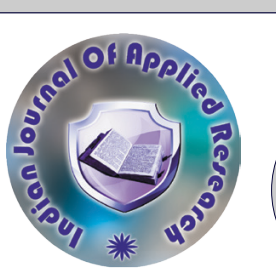

\title{
Obstetrics and Gynaecology
}

UTERO-VAGINAL PROLAPSE AND BLOOD GROUP-A RELATION

\section{Dr Bijan Kumar} Mukhopadhyay*

\section{Saswati chakraborty}

ABSTRACT This study was conducted to analyse the utero- vaginal prolapse and its relation with blood group in MNR Medical College . It was a retrospective analytical study. 188 patients were taken in this study, who were admitted in gynaecology ward with the complaint of third degree utero-vaginal prolapse. Data were tabulated and analysed. It is found that third degree utero vaginal prolapse is more common in $\mathrm{B}+\mathrm{ve}(34.57 \%)$ Blood group and least in $\mathrm{AB}-\mathrm{ve}(.53 \%)$ Blood group.

\section{KEYWORDS : Utero-vaginal prolapse, Blood group}

\section{INTRODUCTION}

Utero-vaginal prolapse is the downward descent of the uterus and vagina. Nulliparous prolapse is seen in $2 \%$ cases $^{(1)}$. Understanding of the pathophysiology and risk factors of the problem is very essential.it may be congenital or acquired. Some diseases are specifically related with specific blood grouping like gestational trophoblastic disease is related with "A blood group ${ }^{(2)}$ ". Blood group "A "has higher incidence of gastric cancer" and Blood group "O" has higher incidence of peptic ulcer $^{(3)}$ This study was done To establish the link between uterovaginal prolapse and blood groups.

\section{METHOD}

The present study was carried out with 188 women, who were admitted to M.N.R. Hospital during the period of 5years with third degree uterine prolapse. Patients on admission were evaluated with clinical and all baseline investigation. All the data was tabulated and analysed.

\section{RESULTS}

of the women studied in this study, maximum number found with the blood group B+ve (65 cases), as shown in table no. -1 and in table no. -2 shows that most of the women with B+ve (34.57\%). and least with the AB-ve (1 case) and only with . $53 \%$.

The total results are tabulated in relation with blood group with $\mathrm{Rh}$ typing, then the number of cases in each group are-

Table No.- 1 Total Number Of Cases In Each Blood Group With Rh Type

\begin{tabular}{|l|l|l|l|}
\hline B+VE -65 & B-VE -7 & O+VE-61 & O-VE -2 \\
CASES & CASES & CASES & CASES \\
\hline A+VE -35 & A+VE- 4 & AB+VE- 13 & AB-VE -1 \\
CASES & CASES & CASES & CASE \\
\hline
\end{tabular}

Table No. -2 Percentage With Each Blood Group With Rh Type

\begin{tabular}{|l|l|l|l|}
\hline B+VE - 34.57\% & O+VE- 32.44\% & A+VE- 18.61\% & AB+VE- 6.91\% \\
\hline
\end{tabular}

\begin{tabular}{|l|l|l|l|}
\hline $\mathrm{B}-\mathrm{VE}-3.72 \%$ & $\mathrm{O}-\mathrm{VE}-1.06 \%$ & $\mathrm{~A}-\mathrm{VE}-2.12 \%$ & $\mathrm{AB}-\mathrm{VE}-.535$ \\
\hline
\end{tabular}

\section{DISCUSSION}

When the data are tabulating as only blood group the data is calculating as
B Group- $38.29 \%$
O Group-33.50\%
A Group $-20.73 \%$
AB Group- $7.44 \%$

The total number of cases and in percentage wise the $\mathrm{B}+\mathrm{ve}$ blood group has the maximum number of cases.

\section{As per the probability equation -}

$\operatorname{Probability}(\mathbf{p})=$ No of individual having specific characteristic $\backslash$ total number of utero-vaginal prolapse ---

$\mathrm{B}+\mathrm{VE}$ cases are 65 .

Probability $=65 / 188=.345$ would be $\mathrm{B}+\mathrm{VE}$ and 655 would be from other blood group.

The results of the present study indicate that the highest percentage of patients belonged to $\mathrm{B}+$ i.e., $34.57 \%$ followed by $\mathrm{O}+(32.44 \%)$. The least was in the $\mathrm{AB}-(.53 \%)$. Further, the percentage in the other groups are $\mathrm{A}+(18.61 \%), \mathrm{AB}+(6.91 \%), \mathrm{B}-(3.72 \%), \mathrm{A}-(2.12 \%), \mathrm{O}-$ $(1.06 \%)$.

AComparison study were made between the blood group in this study and standard Indian population are plotted and the results shown-
In this study

B+VE-34.57\%

$\mathrm{O}+\mathrm{VE}-32.44 \%$

$\mathrm{A}+\mathrm{VE}-18.61 \%$

$\mathrm{AB}+\mathrm{VE}-6.91 \%$

B-VE-3.72\%

O-VE-1.06\%

A-VE- $2.12 \%$

AB-VE-.53\%

\author{
In Indian population( approx. ${ }^{(4)}$ \\ $\mathrm{B}+\mathrm{VE}-32.69 \%$ \\ $\mathrm{O}+\mathrm{VE}-38.75 \%$ \\ $\mathrm{A}+\mathrm{VE}-18.85 \%$ \\ $\mathrm{AB}+\mathrm{VE}-5.72 \%$ \\ B-VE-1.1\% \\ O-VE- $2.0 \%$ \\ A-VE-. $8 \%$ \\ AB-VE-. $2 \%$
}

With this we can conclude that third degree prolapse is more common among B +ve blood group patients. Also, it is least in AB -ve blood group. India has highest percentage of "B" blood group population in the world. Blood group "B" has highest frequency in Northern India. Blood group "O" has the highest frequency in south India. This study was done in south India were the results is getting high frequency.

To confirm this with more authenticity large population based study is needed.

Acknowledgement -

1. Dr. Chitra Patil, Prof Emeritus, Dept. of Obstetrics and Gynaecology, MNR Medical College, Sangareddy, Hyderabad, Telengana. India.

2. Dr. N. Bhavani, Prof. Dept. of Obstetrics and Gynaecology, MNR Medical College, Sangareddy, Hyderabad, Telengana. India.

3. Dr. K.Gayathri, Consultant, Dist. Hospital, Sangareddy, , Telengana. India

\section{REFERENCES-}

1. V.G.Padubidri, Shirish. N. Daftary. Shaw text book of gynaecology. 2009, 14 th edition, Genital prolapse, chapter -25, p-298.

2. V.G.Padubidri, Shirish. N. Daftary. Shaw text book of gynaecology. 2009, 14 th edition, Gestational Trophoblastic Neoplasia's or Diseases, chapter-19, p-227.

Edgren GI, Hjalgrim H, Rostgaard K, Norda R, Wikman A, Melbye M, Nyrén O. Am J Edgren GI, Hjalgrim H, Rostgaard K, Norda R, Wikman A, Melbye M, Nyrén O. Am
Epidemiol 2010 Dec 1; 172(11):1280-5. Doi: 10.1093/aje/kwq299. Epub 2010 Oct 11.

4. Das PK1, Nair SC, Harris VK, Rose D, Mammen JJ, Bose YN, Sudarsanam A. Trop Doct. 2001 Jan;31(1):47-8 